\title{
Internal mechanisms of establishment of the equilibrium state of water-alcohol mixtures in vodka technology
}

\author{
Oleg Kuzmin ${ }^{1}$, Valentyna Zubkova ${ }^{2}$, Tatiana Shendrik ${ }^{3}$, \\ Yurii Korenets ${ }^{4}$, Anton Kuzmin ${ }^{5}$, Pavlo Bilenkyi ${ }^{1}$
}

1 - National University of Food Technologies, Kyiv, Ukraine

2 - Jan Kochanowski University in Kielce, Kielce, Poland

3 - L.M. Litvinenko Institute of Physical-Organic Chemistry and Coal Chemistry of the NAS,

Kyiv, Ukraine

4 - Donetsk National University of Economics and Trade named after Mykhailo Tugan-

Baranovskyi, Kryvyi Rih, Ukraine

5- National Aviation University, Kyiv, Ukraine

Keywords:

Alcohol

Water

Mixture

$\mathrm{Na}$-cationization

Electrochemical

Activation

${ }^{l} H N M R$

Article history:

Received

29.01.2018

Received in

revised form

26.07.2018

Accepted

27.12.2018

\section{Corresponding author:}

Oleg Kuzmin

E-mail:

kuzmin_ovl@

nuft.edū.ua

\section{DOI:}

$10.24263 / 2304$

974X-2017-6-1-

\section{Abstract}

Introduction. The aim of the publication is to study the mechanism of the establishment of relaxation of water-alcohol mixtures (WAM) in the main stages of creating vodka in the application of electrochemical activation (ECA) at the stage of $\mathrm{Na}$-cationization process water softening.

Materials and methods. ${ }^{l} H N M R$ analysis was performed using: $F T$ NMR Bruker Avance II spectrometer (400 MHz); special capillary with acEtOHe- $d_{6}$; high accuracy ampoules № 507-HP; dispenser; ethyl alcohol rectified (EAR); water softened by $\mathrm{Na}$-cationization; WAM from EAR and softened water.

Results and discussion. In this work, the equilibrium state of vodkas in the creation of WAM in the process of ECA of softened water by $\mathrm{Na}$ cationization is investigated. It has been established that electrochemical reactions lead to a change in the system of intermolecular interactions. Charging states of molecules in anolyte and catholyte lead to differences in the electron distribution, which affects the chemical displacements of hydroxyl protons. In relation to the softened water $\left(\delta_{H 2 O}=4.65 \mathrm{ppm}\right)$, the anolyte with $\delta_{H 2 O}=(4.23 ; 4.22) \mathrm{ppm}$ has a displacement of the hydroxyl proton in the «strong field» at $\Delta f=170 \mathrm{~Hz}$. The catholyte with $\delta_{H 2 O}=(4.56$; 4.54) ppm has a displacement in the «strong field» at $\Delta f=40 \mathrm{~Hz}$. It has been proved that the WAM on anolyte $(\mathrm{pH}=2.43)$ and EAR has an acidic medium $(\mathrm{pH}=3.10)$, WAM in a catholyte $(\mathrm{pH}=11.08)$, and EAR has a meadow medium $(\mathrm{pH}=11.75)$. These polar ratios of $\mathrm{H}_{3} \mathrm{O}^{+}$to $\mathrm{OH}^{-}$for anolyte and catholyte lead to a restructuring of the structure in the alcohol/water system. It can be assumed that the proton exchange is accelerated, while there is one general signal of mobile protons $\mathrm{EtOH}+\mathrm{H}_{2} \mathrm{O}$.

On the basis of the study a fundamental difference between the behavior of the WAM and the vodka prepared on softened water and water after ECA treatment was established. Found systems (alcohol/water) with a stable equilibrium, which are characterized by a high degree of generalization of protons, as well as characteristic rates of exchange for it.

Conclusions. The experimental data obtained prove the dependence of the speed and nature of the establishment of the thermodynamic equilibrium due to the relaxation of the WAM. It is shown that relaxation occurs at the simultaneous stabilization of the hydroxyl group of water and ethanol protons. 


\section{Introduction}

Today, ${ }^{l} H N M R$ spectroscopy is the most popular among spectroscopic methods due to its simplicity (Rutledge, 1996) [26] and completeness of information (Majumdar et al., 2017; Richards, Hollerton, 2011) [23, 27], thus accelerating chemical research, especially in the food industry (Abraham, Mobli, 2008) [20]. A large number of articles discuss the use of NMR for research of food products: honey, fruits, juices, vegetables, pastry, cheese, meat, fish, dairy products, starch and alcohol products (Zuriarrain et al, 2015; Minoja, Napoli, 2014; Zhu, 2017; Campo et al, 2016; Pinto et al, 2018; Oh et al, 2018; Shi et al, 2018; Youssouf et al, 2017; Li et al, 2018; Kuballa et al, 2018; Yuan et al, 2017) [1, 2, 5, 6, 9, 10, 11, 17, 25, 28, 32]. This method provides comprehensive information with relatively simple obtaining spectra, thus greatly facilitating and accelerating chemical research (Hu et al, 2010; Nose et al, 2005; Roberts, 2002; Richards, Hollerton, 2011) [8, 18, 24, 27].

Since the first ${ }^{l} H$ NMR spectra of water and ethanol have been obtained more than 60 years, today there are many works (Batta et al, 1997; Albert, 2002; Meusinger, 2010; Rutledge, 1996; Holzgrabe et al, 2008) [7, 12, 21, 26, 29] in which the spectra of water and ethanol are given - which are understandble from the analytical point of view of the substance. But these relatively simple molecules have a large variety of details that occupy a deserved place both in works (Arnold, 2002; Becker et al, 2002; Oliveira et al, 2007; Ababneh, 2018; Richards, Hollerton, 2011; Xu et al, 2012; Mori et al, 2018) [3, 4, 19, 22, 27, $30,31]$ and are of interest to our work (Kuzmin et al, 2017) [15, 16].

We will consider a complex of issues related to intermolecular proton exchange. The hydroxyl protone of ethanol can be exchanged with free $\mathrm{H}^{+}$ions in the matrix, which are generated by the introduced water or by residual quantities of acid (Arnold, 2002; Becker et al, 2002; Abraham, Mobli, 2008) [3, 4, 20]. The rate of exchange is proportional to the number of free ions $\mathrm{H}^{+}$, so the actual location of the center of the signal depends on the availability of an alternative exchange point (water), as well as on the difference in chemical changes in the protons of the two milieus (Arnold, 2002; Richards, Hollerton, 2011) [3, 27].

Previously, we have conducted primary research of ${ }^{l} H$ NMR of water-alcohol mixtures (WAM), which were described in the work of Kuzmin et al, 2017 [15, 16]. The obtained results give grounds to assert a fundamental difference in the behavior of the WAM prepared from the alcohol and water passing through various processes. This may indicate the presence of such features as separate signals of $\mathrm{OH}$-protons of $\mathrm{H}_{2} \mathrm{O}$ and $\mathrm{EtOH}$. Also abnormal waveforms of $\mathrm{CH}_{3}$ and $\mathrm{CH}_{2}$ characterize a product with a lowered tasting properties. The presence of the combined signal of $\mathrm{H}_{2} \mathrm{O}+(\mathrm{EtOH})$ and a «clear» form of $\mathrm{CH}_{3}$ and $\mathrm{CH}_{2}$ signals (triplet - for $\mathrm{CH}_{3}$, quartet - for $\mathrm{CH}_{2}$ ) - characterizes the WAM with the best tasting properties.

Thus, in the work of Kuzmin et al, 2017 [15, 16] established experimental evidence or instilment nature/(non- installment) of thermodynamic balance, taking into account the organoleptic characteristics of WAM in dependence on water treatment method and time of system's functioning. However, the questions related to internal mechanism's specification and the rate of establishment of thermodynamic balance depending on type of water used in the process of creating the WAM are remain unsolved.

Therefore, the additional research is required for a detailed study of internal mechanism of thermodynamic balance and insurance in obtaining high quality vodka products - for each type of water separately.

Conducting a set of technical solutions at the main stages of production of vodka, due to electrochemical activation (ECA) of technological water, will allow us to study the mechanism for establishing the equilibrium state of WAM by stabilizing the position of $\mathrm{OH}$ protons of ethanol and water, using ${ }^{l} H N M R$ spectroscopy. Since there is no such information 
in the literature, the purpose of the work was to study the mechanism of establishing the thermodynamic equilibrium - the relaxation of the WAM at the major stages of creating vodka when applying ECA at the stage of $\mathrm{Na}$-cationization softening of technological water to predict the quality of the final product.

For the set goal, the following tasks were solved:

- to obtain experimental evidence of the rate and nature of the establishment of the thermodynamic equilibrium of WAM;

- to establish a mechanism of thermodynamic equilibrium - the relaxation of WAM;

- to investigate the stabilization of the hydroxyl group of water and ethanol protons.

\section{Materials and methods}

Scheme of conducting research (basic scheme of the experimental stand, the scheme of sample preparation for the ${ }^{l} H N M R$ study and block diagram of the ${ }^{l} H N M R$ spectrometer) is presented in Figure 1.

The following devices, materials and raw materials were used for research:

- dispenser (15); ampoules $5 \mathrm{~mm}$ (400 MHz) with specimens (16); capillaries with deuteroacEtOHe (DAC) (17); ampoules with capillary (18) (Figure 1, b);

- drinking water (0.0) with characteristics: hydrogen index 6.91 unit $\mathrm{pH}$; redox potential (ORP) «+»269.0 mV; mass concentration (MC) $\mathrm{MC}_{\mathrm{Ca}}-104.342 \mathrm{mg} / \mathrm{dm}^{3} ; \mathrm{MC}_{\mathrm{Mg}}-22.835$ $\mathrm{mg} / \mathrm{dm}^{3} ; \mathrm{MC}_{\mathrm{Na}}-91.966 \mathrm{mg} / \mathrm{dm}^{3}$; total hardness $-8.04 \mathrm{mmol} / \mathrm{dm}^{3}$; total alkalinity -5.38 $\mathrm{mmol} / \mathrm{dm}^{3}$;

- softened water (1.0) with characteristics: hydrogen index 7.18 unit $\mathrm{pH}$; ORP «+» 288.0 $\mathrm{mV} ; \mathrm{MC}_{\mathrm{Ca}}-0 \mathrm{mg} / \mathrm{dm}^{3} ; \mathrm{MC}_{\mathrm{Mg}}-0 \mathrm{mg} / \mathrm{dm}^{3} ; \mathrm{MC}_{\mathrm{Na}}-266.131 \mathrm{mg} / \mathrm{dm}^{3}$; total hardness -0.05 $\mathrm{mmol} / \mathrm{dm}^{3}$; total alkalinity $-4.12 \mathrm{mmol} / \mathrm{dm}^{3}$;

- anolyte (1.2) with characteristics: hydrogen index 2.43 unit $\mathrm{pH}$; ORP «+» $451.0 \mathrm{mV}$; $\mathrm{MC}_{\mathrm{Ca}}-0 \mathrm{mg} / \mathrm{dm}^{3} ; \mathrm{MC}_{\mathrm{Mg}}-0 \mathrm{mg} / \mathrm{dm}^{3} ; \mathrm{MC}_{\mathrm{Na}}-156.626 \mathrm{mg} / \mathrm{dm}^{3}$; total hardness -0.90 $\mathrm{mmol} / \mathrm{dm}^{3}$; total alkalinity $-0.00 \mathrm{mmol} / \mathrm{dm}^{3}$;

- catholyte (1.1) with characteristics: hydrogen index 11.08 unit pH; ORP «+» $44.0 \mathrm{mV}$; $\mathrm{MC}_{\mathrm{Ca}}-0 \mathrm{mg} / \mathrm{dm}^{3} ; \mathrm{MC}_{\mathrm{Mg}}-0 \mathrm{mg} / \mathrm{dm}^{3} ; \mathrm{MC}_{\mathrm{Na}}-380.009 \mathrm{mg} / \mathrm{dm}^{3}$; total hardness -0.15 $\mathrm{mmol} / \mathrm{dm}^{3}$; total alkalinity $-10.85 \mathrm{mmol} / \mathrm{dm}^{3}$;

- ethyl alcohol rectified (EAR) of the class «Lux» (2.0): volume fraction of ethanol $96.37 \%$, at $\mathrm{T}=293 \mathrm{~K} ; \mathrm{MC}_{\text {aldehydes }}-1.28 \mathrm{mg} / \mathrm{dm}^{3} ; \mathrm{MC}_{\text {fusel oil }}-1.47 \mathrm{mg} / \mathrm{dm}^{3} ; \mathrm{MC}_{\text {esters }}-1.30$ $\mathrm{mg} / \mathrm{dm}^{3}$; volume fraction of methanol $-0.0022 \%$;

- WAM for EAR of a class «Lux» and water softened by $N a$-cationization (3.0): volume fraction of ethanol - 39.90\%; hydrogen index 7.84 unit $\mathrm{pH}$; ORP - «-»35 mV; $\mathrm{MC}_{\text {aldehydes }}$ $-1.31 \mathrm{mg} / \mathrm{dm}^{3} ; \mathrm{MC}_{\text {fusel oil }}-1.41 \mathrm{mg} / \mathrm{dm}^{3} ; \mathrm{MC}_{\text {esters }}-1.41 \mathrm{mg} / \mathrm{dm}^{3}$; volume fraction of methanol $-0.0020 \%$; alkalinity $-2.40 \mathrm{ml}$; tasting score -9.49 points;

- WAM on softened water - anolyte (3.2): volume fraction of ethanol - 39.91\%; hydrogen index 3.10 unit $\mathrm{pH}$; ORP - «+»146 mV; $\mathrm{MC}_{\text {aldehydes }}-1.80 \mathrm{mg} / \mathrm{dm}^{3} ; \mathrm{MC}_{\text {fusel oil }}-1.26$ $\mathrm{mg} / \mathrm{dm}^{3} ; \mathrm{MC}_{\text {esters }}-1.55 \mathrm{mg} / \mathrm{dm}^{3}$; volume fraction of methanol $-0.0022 \%$; alkalinity $0.00 \mathrm{ml}$; tasting score -9.51 points;

- WAM on softened water - catholyte (3.1): volume fraction of ethanol - 39.95\%; hydrogen index 11.75 unit $\mathrm{pH}$; ORP - «-» $174 \mathrm{mV} ; \mathrm{MC}_{\text {aldehydes }}-1.43 \mathrm{mg} / \mathrm{dm}^{3} ; \mathrm{MC}_{\text {fusel oil }}-$ $1.20 \mathrm{mg} / \mathrm{dm}^{3} ; \mathrm{MC}_{\text {esters }}-1.42 \mathrm{mg} / \mathrm{dm}^{3}$; volume fraction of methanol $-0.0021 \%$; alkalinity $-2.40 \mathrm{ml}$; tasting score -9.42 points; 


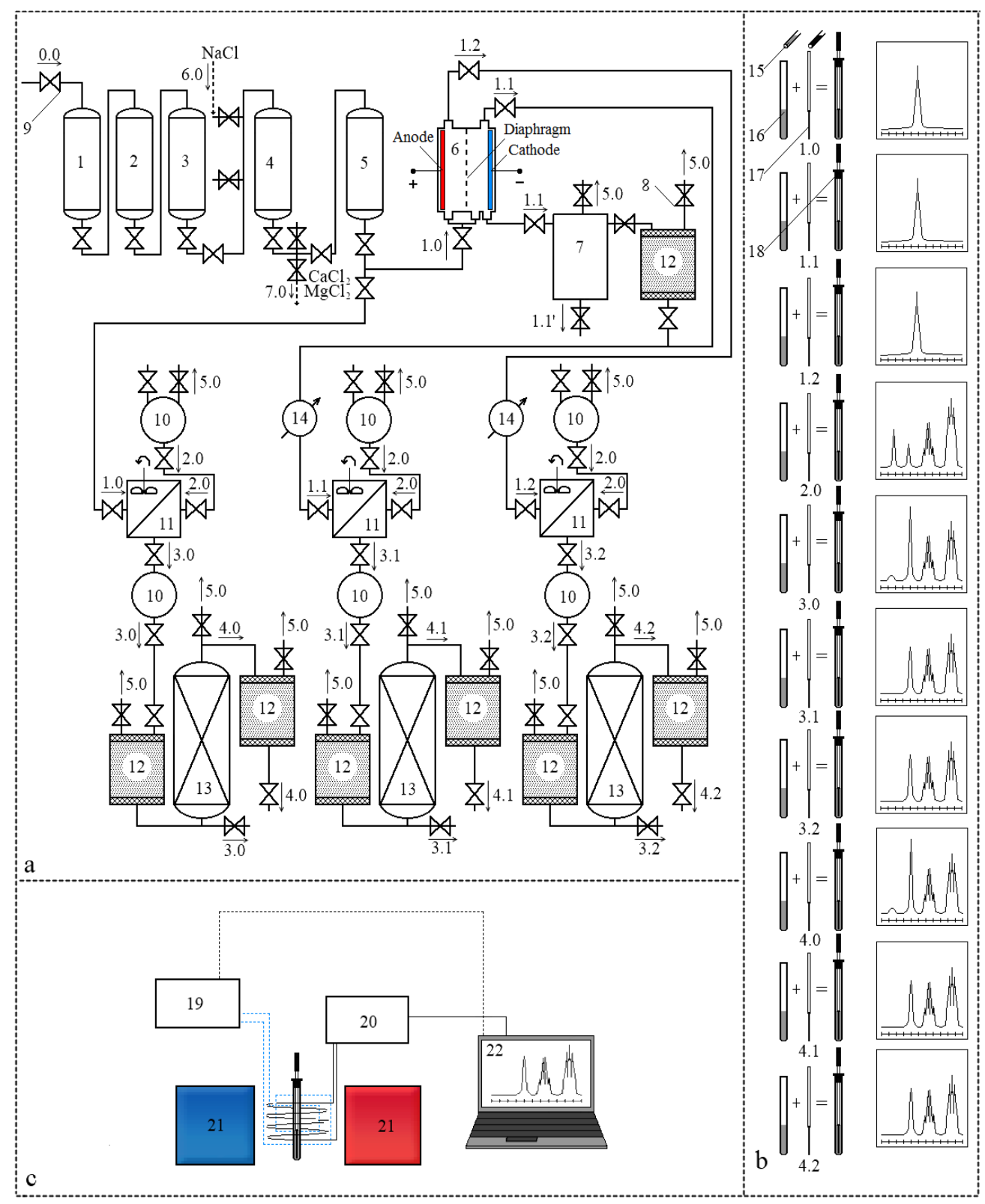

Figure 1. Scheme of research:

a - the principle scheme of the experimental stand;

$\mathrm{b}$ - sample preparation scheme for ${ }^{1} H N M R$ study;

c - block diagram of a ${ }^{l} H N M R$ spectrometer;

0.0-7.0 - streams; 1-14-technological equipment; $15-22$ - laboratory equipment 
- WAM on EAR and water softened at the expense of $\mathrm{Na}$-cationization after treatment with activated carbon (AC) (4.0): volume fraction of ethanol - 39.81\%; hydrogen index 9.14 unit $\mathrm{pH} ; \mathrm{ORP}-\langle+\rangle 122 \mathrm{mV} ; \mathrm{MC}_{\text {aldehydes }}-1.72 \mathrm{mg} / \mathrm{dm}^{3} ; \mathrm{MC}_{\text {fusel oil }}-1.34 \mathrm{mg} / \mathrm{dm}^{3} ; \mathrm{MC}_{\text {esters }}$ $-1.82 \mathrm{mg} / \mathrm{dm}^{3}$; volume fraction of methanol $-0.0023 \%$; alkalinity $-2.3 \mathrm{ml}$; tasting score -9.63 points;

- WAM on softened water - anolyte after AC (4.2): volume fraction of ethanol - $39.82 \%$; hydrogen index 3.12 unit $\mathrm{pH}$; ORP - «+»360 mV; $\mathrm{MC}_{\text {aldehydes }}-4.54 \mathrm{mg} / \mathrm{dm}^{3} ; \mathrm{MC}_{\text {fusel oil }}-$ $1.57 \mathrm{mg} / \mathrm{dm}^{3} ; \mathrm{MC}_{\text {esters }}-3.52 \mathrm{mg} / \mathrm{dm}^{3}$; volume fraction of methanol $-0.0024 \%$; alkalinity $-0.0 \mathrm{ml}$; tasting score -9.61 points;

- WAM on softened water - catholyte after AC (4.1): volume fraction of ethanol $-39.80 \%$; hydrogen index 10.45 unit $\mathrm{pH}$; ORP $-\ll+» 92 \mathrm{mV} ; \mathrm{MC}_{\text {aldehydes }}-2.22 \mathrm{mg} / \mathrm{dm}^{3} ; \mathrm{MC}_{\text {fusel oil }}-$ $1.44 \mathrm{mg} / \mathrm{dm}^{3} ; \mathrm{MC}_{\text {esters }}-1.60 \mathrm{mg} / \mathrm{dm}^{3}$; volume fraction of methanol $-0.0024 \%$; alkalinity $-2.4 \mathrm{ml}$; tasting score -9.65 points;

Methods: ${ }^{I} H$ NMR spectroscopy; methods for assessing physical-chemical and organoleptic characteristics of water, EAR, WAM and vodka.

Work methodology of ${ }^{l} H$ NMR (Kuzmin et al, 2017) $[15,16]$ : using the dispenser (15) in the ampoule (16) the test specimen is given. Necessary for the system LOCK - deuterial stabilization NMR spectrometer DAC - external standard, which is separated from the test substance, is introduced into the ampule (16) in the capillaries of a special form (17); in accordance with the method of recording ${ }^{1} H N M R$ spectra, the spectrum of the sample in the DAC (18) is recorded and processed using the Bruker TopSpin v2.6 program.

Apparatus. For the ${ }^{l} H$ NMR study, the Fourier NMR spectrometer Bruker Avance II 400 MHz (Figure 1, c) (19-22) was used.

In Figure 1 a, the principal scheme of the experimental stand with the diaphragm electrochemical reactor is given.

Drinking water (0.0) through the open tap (9) enters the line for preparation of technological water, which consists of the following elements:

- mechanical filter (1) of polypropylene fiber with a filtration rating of $5 \mu \mathrm{m}$, which removes mechanical impurities of more than $5 \mu \mathrm{m}$ from the water;

- carbon filter (2) with porous carbon materials (PCM), which is prepared from alternative materials - food industry wastes by method of chemical activation using $\mathrm{H}_{3} \mathrm{PO}_{4}$ (Kuzmin O., Shendrik T., Zubkova V., 2017) [14], which provides clearing of active chlorine, iron;

- a mechanical filter (3) with a filtration rating of $1 \mu \mathrm{m}$ which removes mechanical impurities from the water, which are in the form of weighted particles of varying degrees of dispersion sized by more than $1 \mu \mathrm{m}$;

- a filter with ion exchange resin cationic type granules (4). The installation is equipped with mechanisms of automatic regeneration of ion exchange resin $\mathrm{NaCl}(6.0)$ and a drain of water concentrate from $\mathrm{CaCl}_{2}$ and $\mathrm{MgCl}_{2}$ (7.0);

- a barrier filter (5), which is designed for control softened water filtration before supplying reverse osmosis with a particle lag rating of $1 \mu \mathrm{m}$.

\section{Results and discussions}

On the ECA preparation line, softened water enters the electrochemical reactor (6), the anodic and cathodic space of which is separated by a porous partition, a diaphragm that is permeable to ions and impervious to products of electrolysis. In this case, the arrival of electrons in water occurs near the cathode, and the removal of electrons from water - near 
the anode, which leads to the formation in a cathode chamber - a catholyte (1.1), and in the anode - anolyte (1.2).

For drainage and filtration of the catholyte concentrate (1.1') there is an additional line with a receiving capacity (7), a sand-filter (12) and air cocks (8) - for air separation (5.0).

The ECA process leads to an increase in the water temperature to $T_{1.1-1.2}=310 \mathrm{~K}$, which is unacceptable for the manufacture of WAMs, so the water flows $(1.1,1.2)$ are additionally cooled using a chiller (14).

On the WAM preparation line from the pressure tanks (10) to the sorting tanks the EAR (2.0) and then the water (1.0-1.2) are added (11), where they are mixed by high-speed propeller mixers with the asynchronous electric motor Vemat VTB80B-8. In the process of mixing there is contractionof the total volume of the WAM with heat release. After mixing using the density analyzer "Anton Paar DMA 4500», if the strength of the WAM is determined with deviations from the given, adjust it, re-mix and carry out sampling (3.03.2).

After mixing, the WAM enters the pressure vessels (10), after which it is filtered on the sand filters (12) and treated with AC in adsorbers (13). AC used from pyrolyzed wood wastes, obtained by the method of alkaline activation of $\mathrm{KOH}$ (Kuzmin O., Tamarkina J., Shendrik T., Zubkova V. et al, 2017) [13]. In order to get rid of small particles of coal, WAM (vodka) is filtered again and sampled (4.0-4.2).

In Figure 2-11 shows one-dimensional ${ }^{l} H N M R$ spectra of hydroxyl protons of the studied substances, taking into account the chemical shift.

The studies used EAR with a volume fraction of ethanol $-96.37 \%$ and water $-3.63 \%$, so the ${ }^{l} H N M R$ spectra of $O H$-proton WAMs are represented by two separate signals of ethanol $\mathrm{EtOH}$ and $\mathrm{H}_{2} \mathrm{O}$ water (Figure 2). The component $\mathrm{EtOH}$ is a symmetric singlet with an expanded base and an apex of the correct form with a chemical shift $\delta_{E t O H}=5.65 \mathrm{ppm}$. The $\mathrm{H}_{2} \mathrm{O}$ component is a singlet from $\delta_{\mathrm{H} 2 \mathrm{O}}=4.85 \mathrm{ppm}$. The difference in chemical shifts between $\mathrm{EtOH}$ and $\mathrm{H}_{2} \mathrm{O}$ is $\Delta \delta=0.80 \mathrm{ppm}(\Delta f=320 \mathrm{~Hz})$.

The ${ }^{l} H N M R$ spectrum of softened water due to $N a$-cationization (Figure 3 ) is presented as a singlet with an expanded base and an irregular vertex and $\delta_{\mathrm{H} 2 \mathrm{O}}=4.65 \mathrm{ppm}$. The ${ }^{l} H N M R$ spectrum of water softened by $\mathrm{Na}$-cationization after ECA: anolyte is a singlet from $\delta_{H 2 O}=(4.23 ; 4.22) \mathrm{ppm}$ (Figure 4$)$; catholyte is a singlet from $\delta_{H 2 O}=(4.56 ; 4.54) \mathrm{ppm}$ (Figure 5). In relation to the water softened by $\mathrm{Na}$-cationization, anolyte has displacement in the «strong field» at $\Delta \delta=0.425 \mathrm{ppm}(\Delta f=170 \mathrm{~Hz})$, catholyte has a displacement of the hydroxyl proton in a «strong field» with an average value of $\Delta \delta=0.10 \mathrm{ppm}(\Delta f=40 \mathrm{~Hz})$.

In the process of mixing the EAR class «Lux» (Figure 2) with water softened by $\mathrm{Na}$ cationization (Figure 3), the WAM is formed (Figure 6), whose ${ }^{l} H N M R$ spectra are represented by one single singlet $-\mathrm{EtOH}+\mathrm{H}_{2} \mathrm{O}$ with an expanded base and the vertex of the correct form and $\delta_{E t O H+H 2 O}=4.41 \mathrm{ppm}$. The difference in chemical shifts between $E t O H$ and $\mathrm{H}_{2} \mathrm{O}$ is $\Delta \delta=0.0 \mathrm{ppm}$.

When creating a WAM (Figure 7) on an EAR of the class «Lux» (Figure 2) with the anolyte (Figure 4), the proton spectra are represented by one single singlet $-\mathrm{EtOH}+\mathrm{H}_{2} \mathrm{O}$ with $\delta_{E t O H+H 2 O}=(4.82 ; 4.81) \mathrm{pmm}$. The form of the $\mathrm{EtOH}+\mathrm{H}_{2} \mathrm{O}$ signal is a distorted gaussian, with an extended base and a certain asymmetry of the vertex, which has one principal peak peak and one additional low-peak peak.

When creating a WAM (Figure 8) in the catholyte (Figure 5), the proton spectra are characterized by a total singlEtOH $\mathrm{EtOH}+\mathrm{H}_{2} \mathrm{O}$ with $\delta_{\mathrm{EtOH}+\mathrm{H}_{2} \mathrm{O}}=(4.76 ; 4.75) \mathrm{pmm}$. 


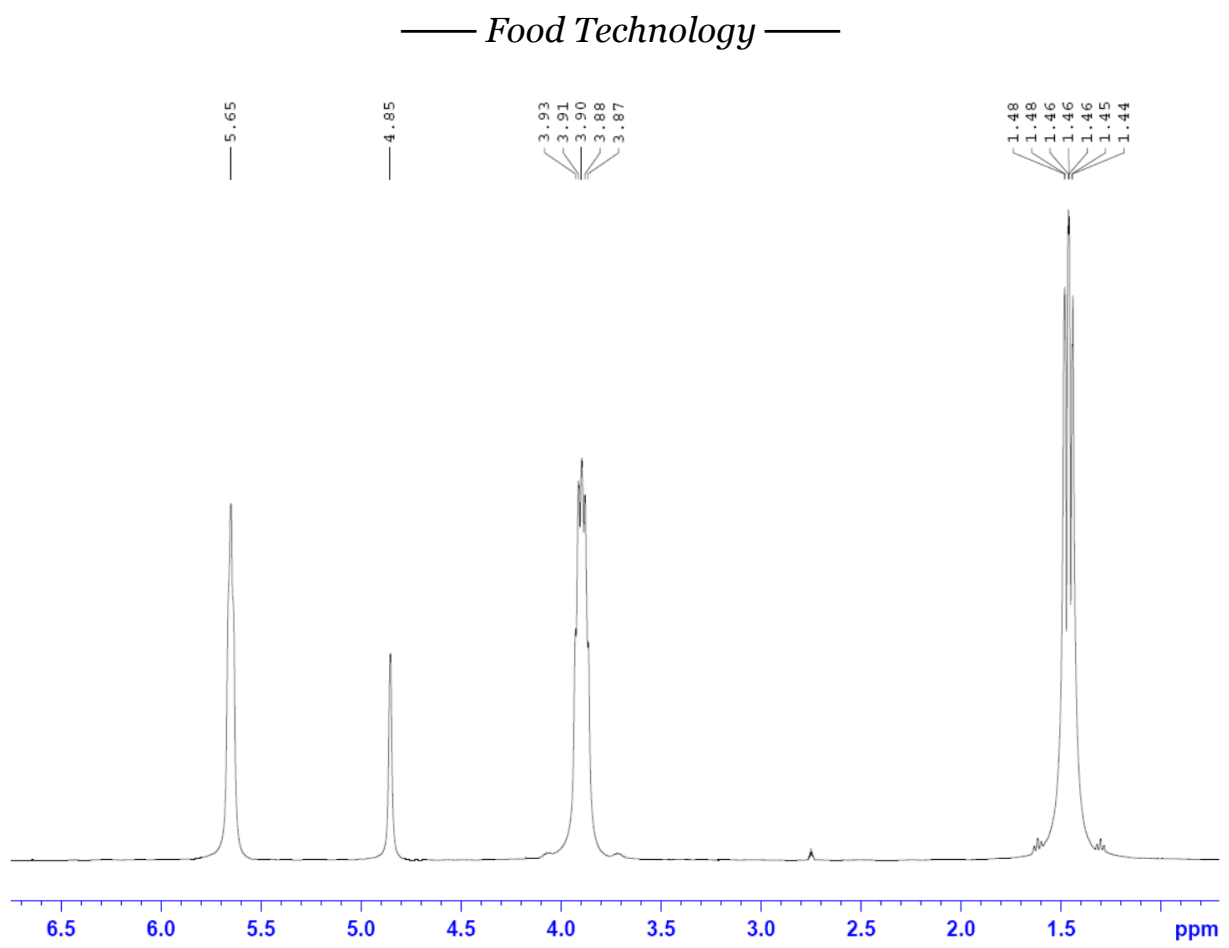

Figure 2. ${ }^{1} \mathrm{H} N M R$ spectra of proton groups EAR: $\mathrm{CH}_{3} ; \mathrm{CH}_{2} ; \mathrm{H}_{2} \mathrm{O} ; \mathrm{EtOH}$

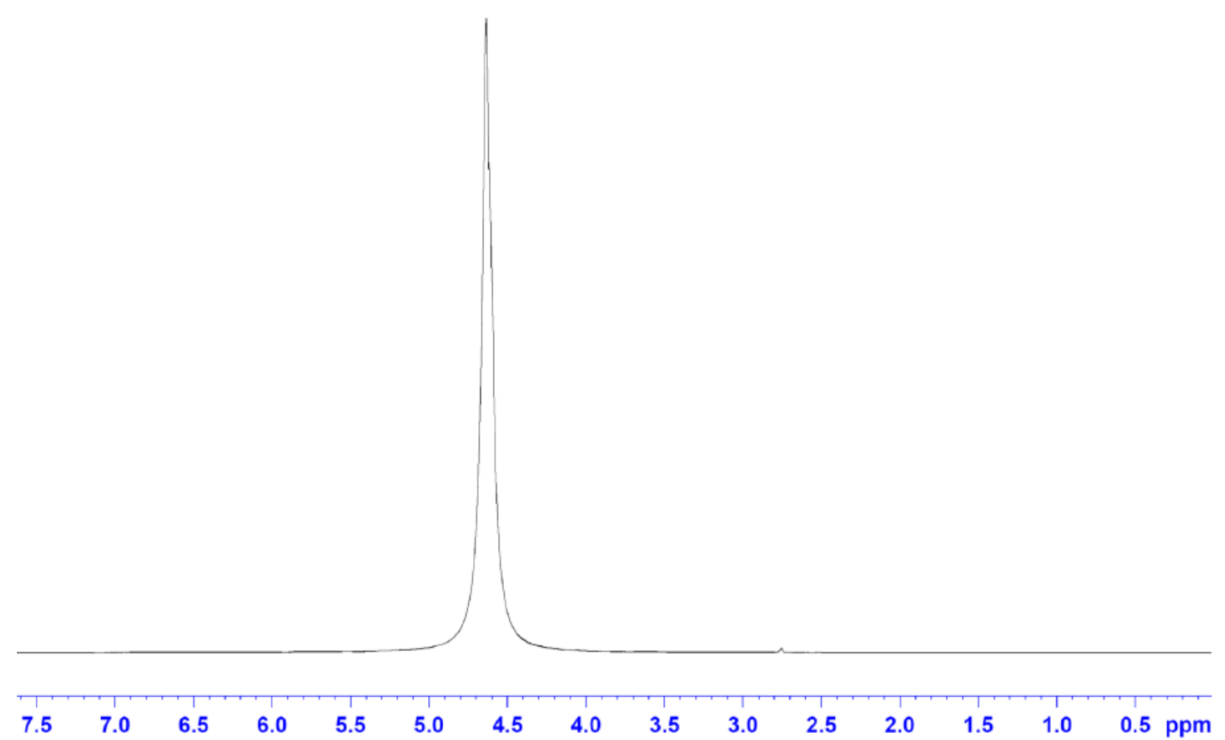

Figure 3. ${ }^{1} \mathrm{H} \mathrm{NMR}$ spectra of hydroxyl proton of $\mathrm{Na}$-cationization softening of technological water 


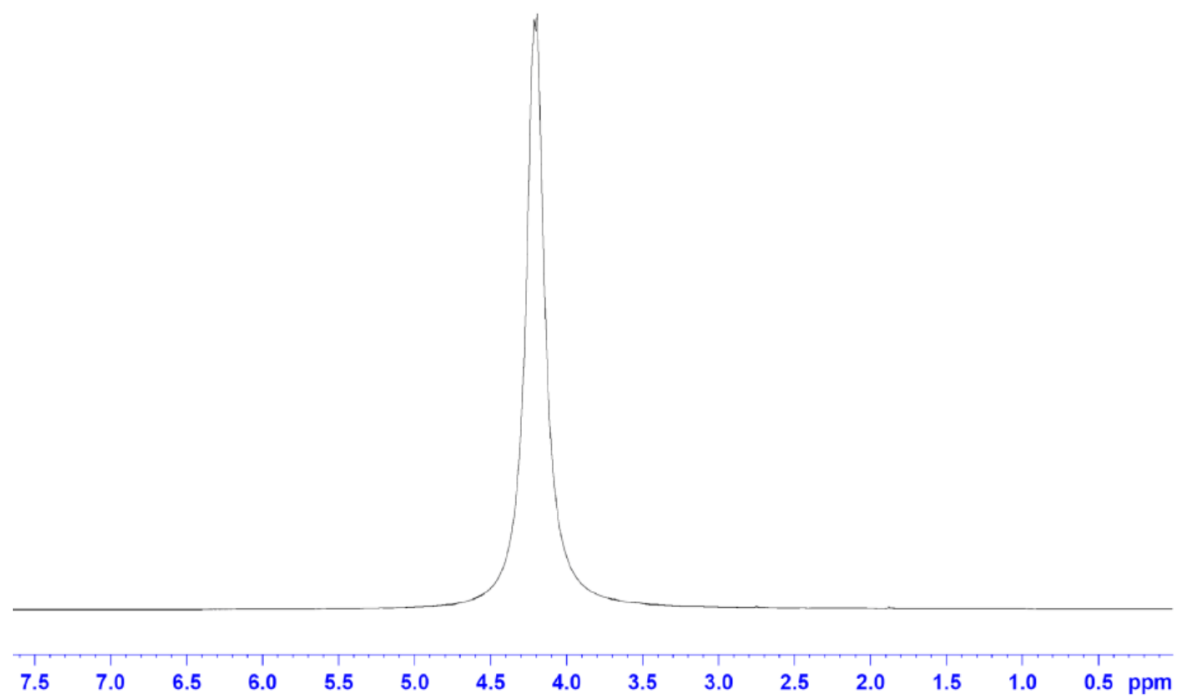

Figure 4. ${ }^{1} \mathrm{H}$ NMR spectra of hydroxyl proton of water softened by $\mathrm{Na}$-cationization after ECA (anolyte)

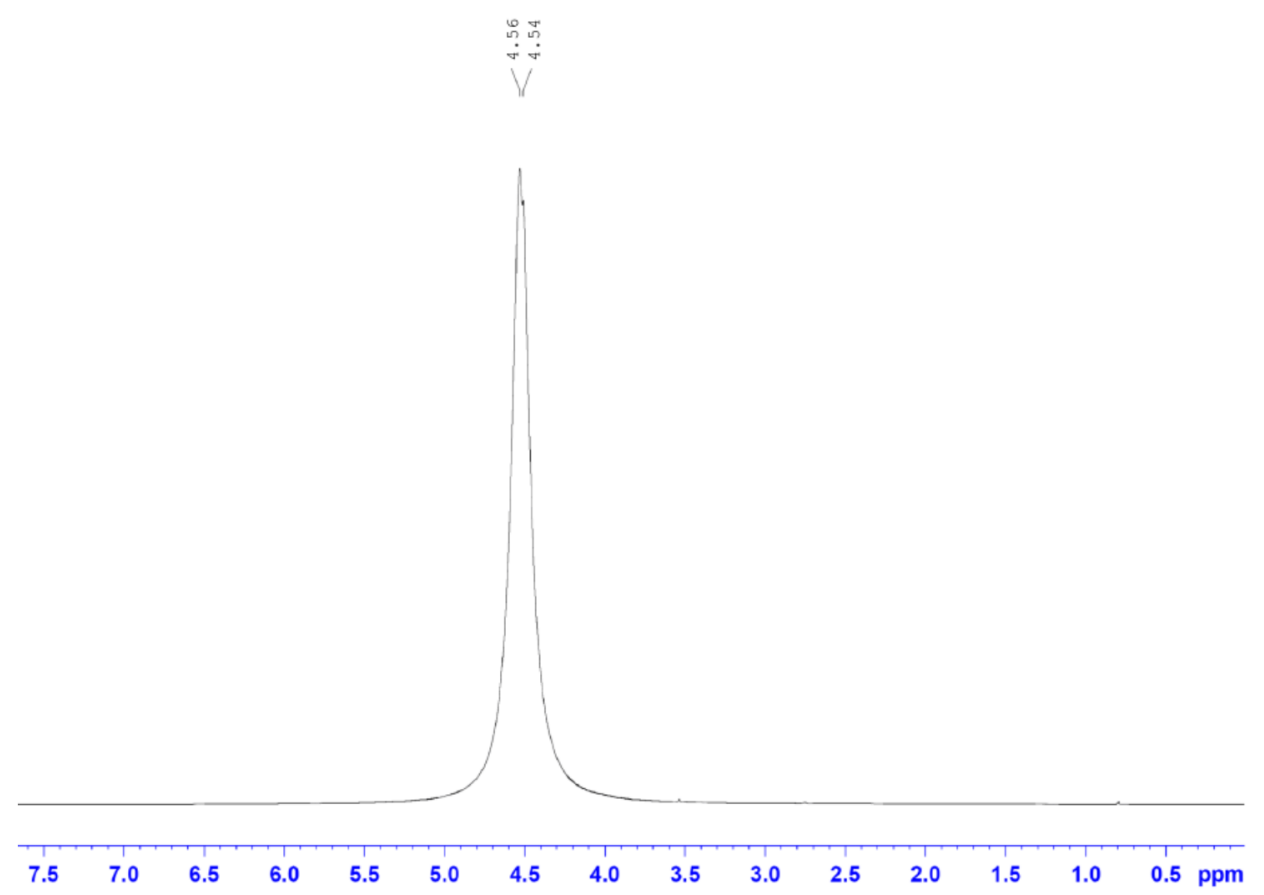

Figure 5. ${ }^{1} \mathrm{H} N \mathrm{NM}$ spectra of hydroxyl proton of water softened by $\mathrm{Na}$-cationization after ECA (catholyte) 


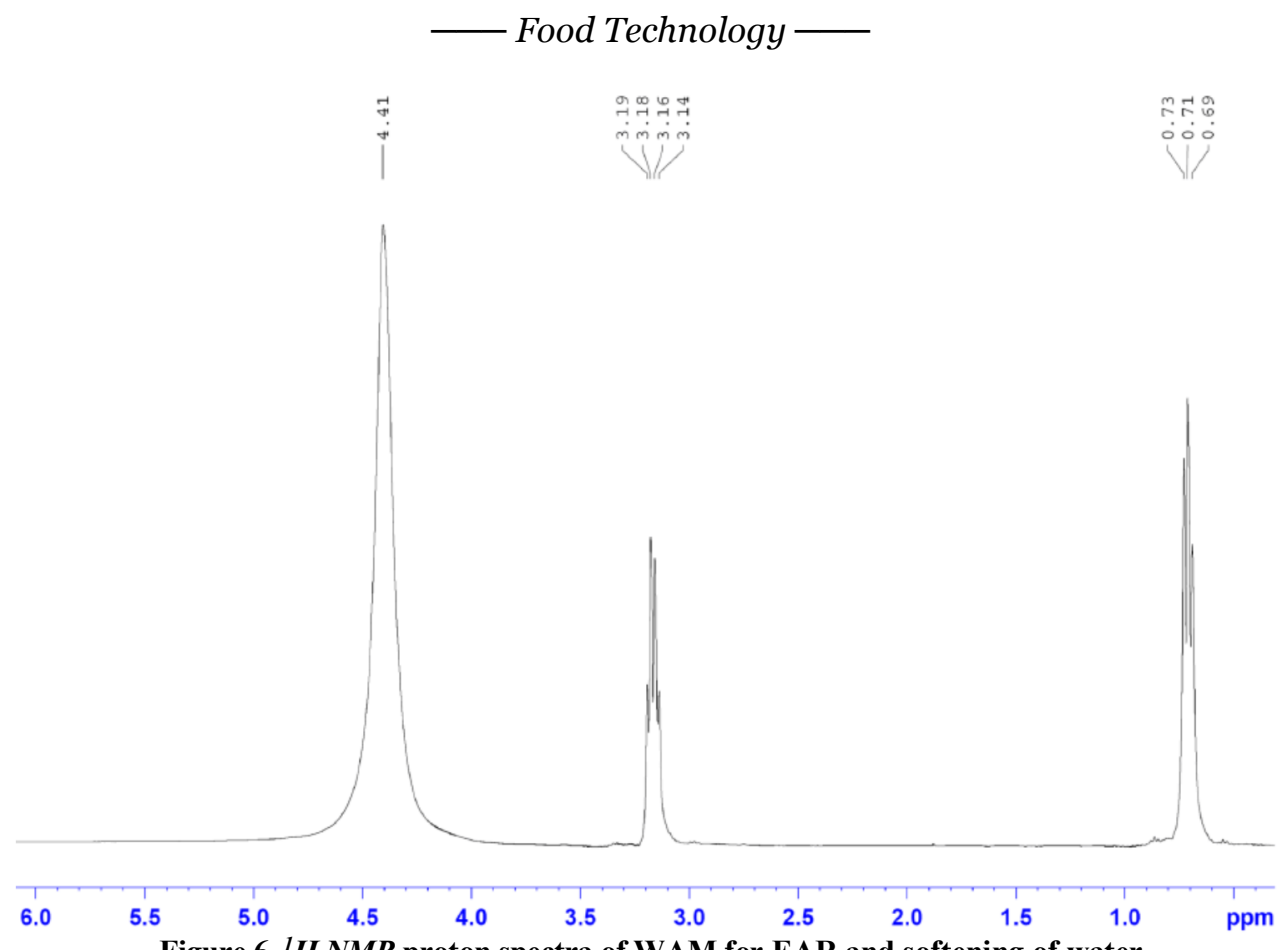

Figure 6. ${ }^{1} \mathrm{H} N M R$ proton spectra of WAM for EAR and softening of water

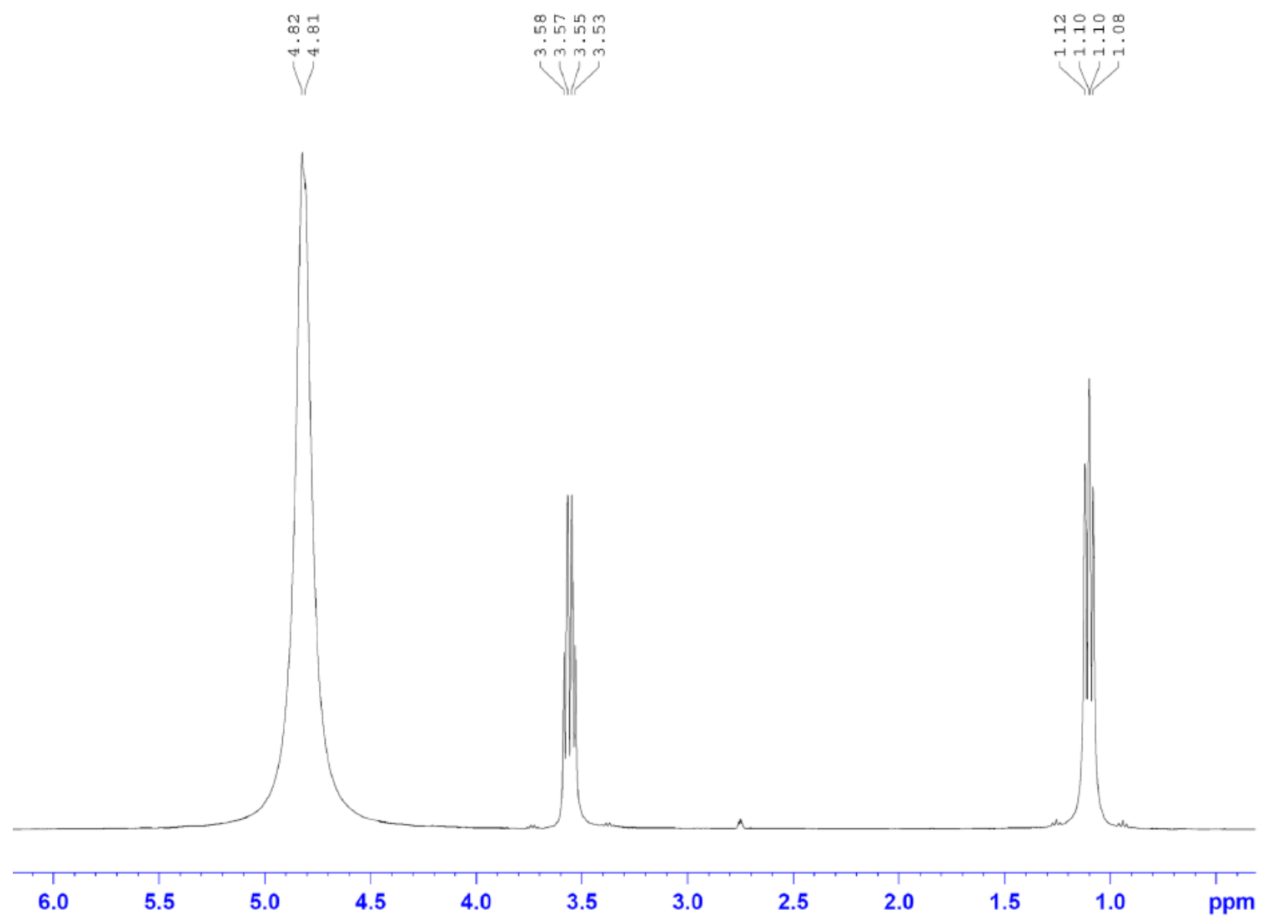

Figure $7 .{ }^{1} H$ NMR proton spectra of WAM for EAR and softening of water after ECA (anolyte) 


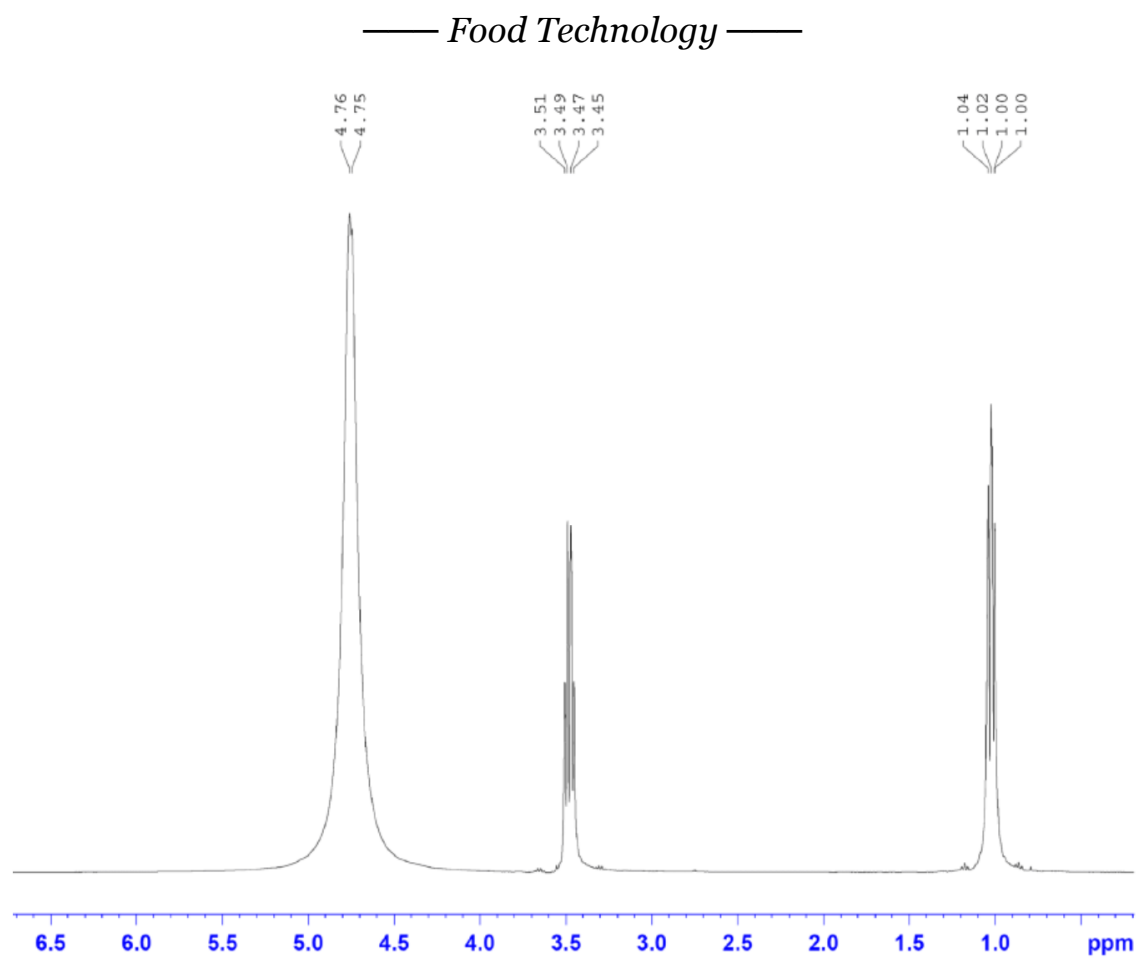

Figure 8. ${ }^{1} \mathrm{H}$ NMR proton spectra of WAM for EAR and softening of water after ECA (catholyte)

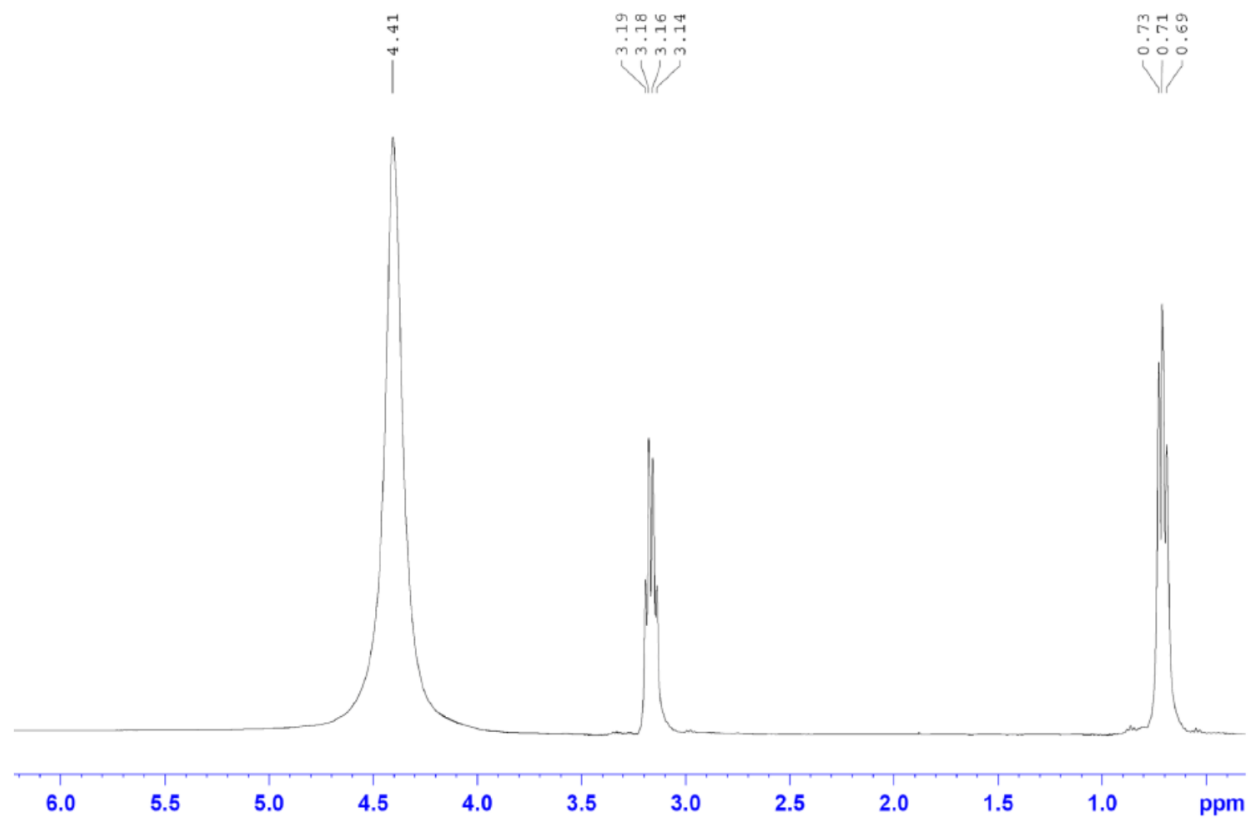

Figure 9. ${ }^{1} \mathrm{H} N M R$ proton spectra of WAM for EAR and softening of water after treatment with $\mathrm{AC}$ 


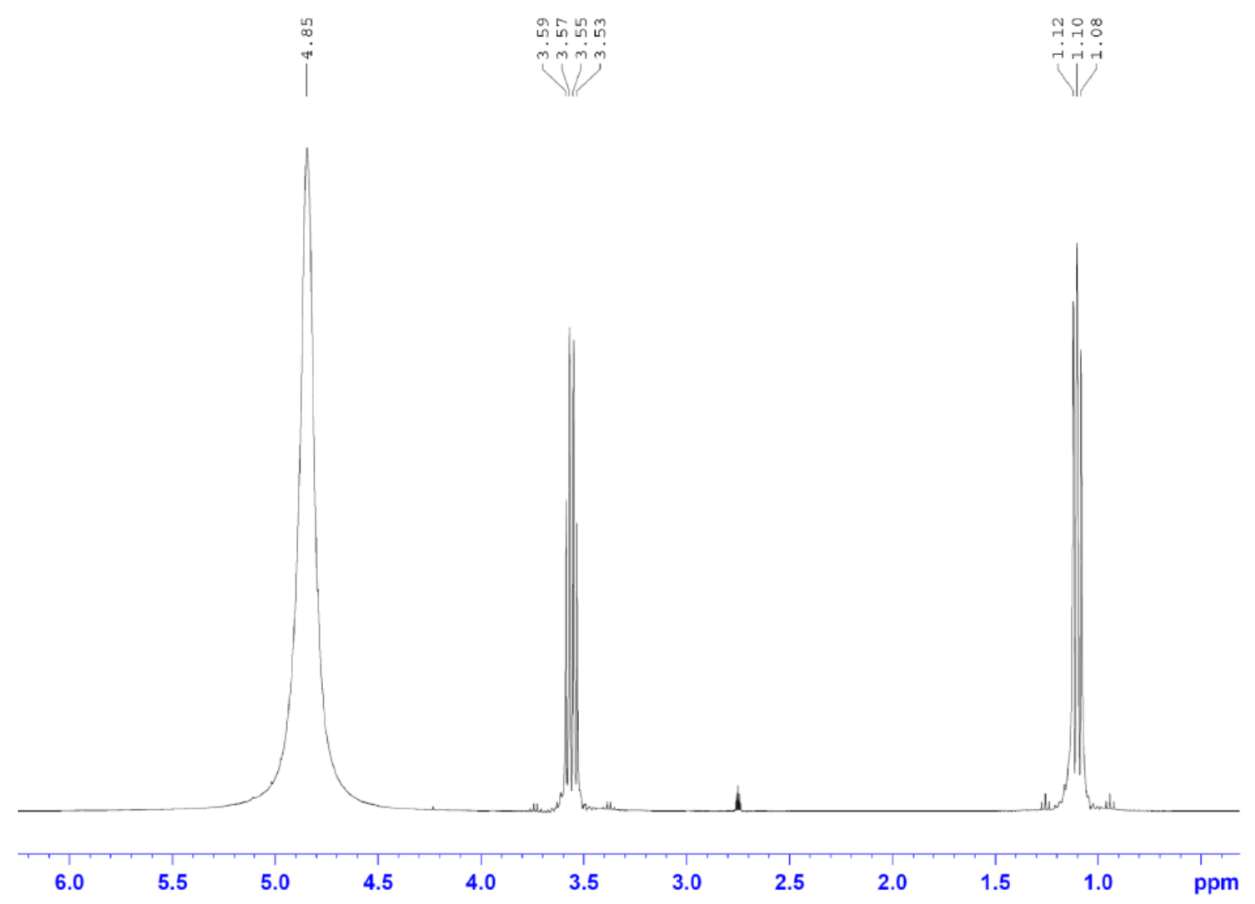

Figure 10. ${ }^{1} H$ NMR proton spectra of WAM for EAR and anolyte after treatment with AC

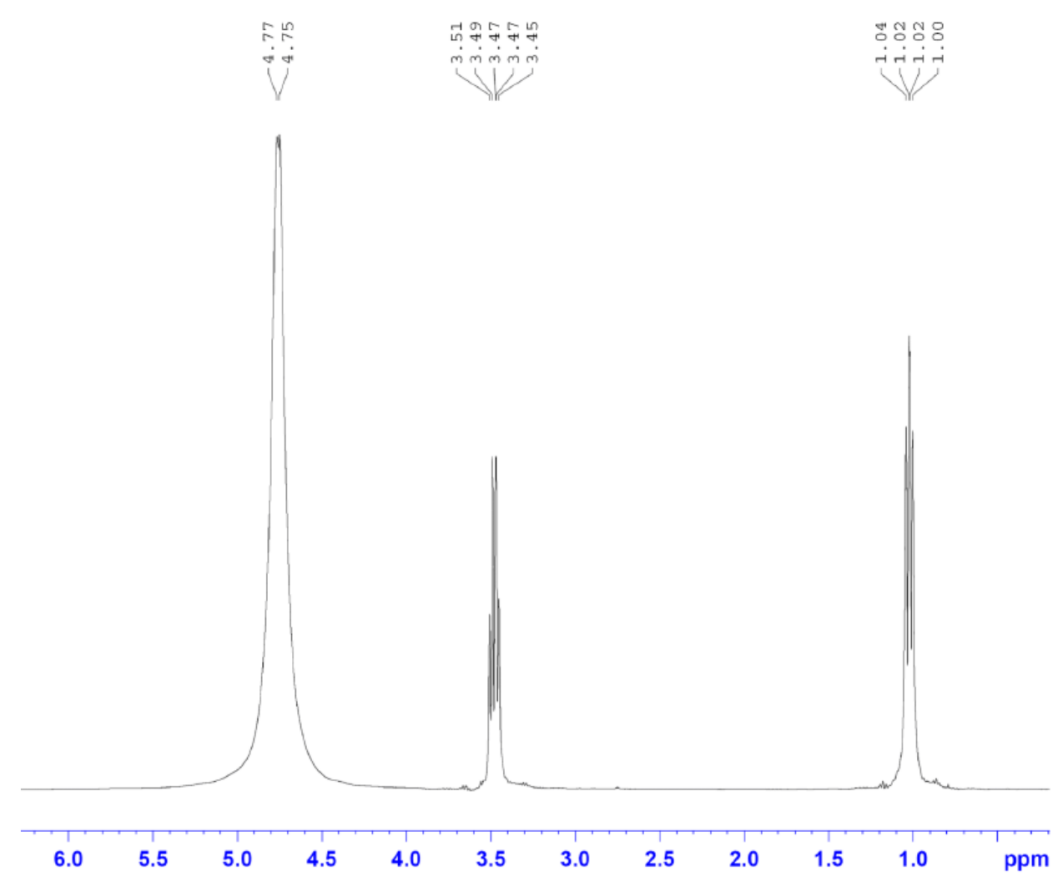

Figure 11. ${ }^{1} \mathrm{H}$ NMR proton spectra of WAM for EAR and catholyte after treatment with AC 
It can be concluded that in the process of creating a WAM in water softened by $\mathrm{Na}$ cationization with a pH level of 7.18 and an EAR of the «Lux» class, the obtained WAM has a $\mathrm{pH}$ level of 7.84, which characterizes the reduced concentration of ions of hydroxonium $\mathrm{H}_{3} \mathrm{O}^{+}$in relation to $\mathrm{OH}^{-}$hydroxyl ions. At constant concentration of alcohol in WAM (volume fraction of ethanol - 39.94\%) and thermostating system at ${ }^{l} H$ studies $(T=296.5 \mathrm{~K})$ there is an instantaneous structuring of the system, the proton exchange is so fast that there is only one general signal of hydroxyl protons ethanol $(\mathrm{EtOH})$ and water $\left(\mathrm{H}_{2} \mathrm{O}\right)$, although with a certain asymmetry.

At the expense of the ECA when WAM is created in anolyte with a pH level of 2.43 and an EAR of the Lux class, the WAM obtained has a pH level of 3.10, which characterizes the acidic medium. WAM on a catholyte with a pH level of 11.08 has a strongly alkaline medium $(\mathrm{pH}=11.75)$.

These polar ratios of $\mathrm{H}_{3} \mathrm{O}^{+}$to $\mathrm{OH}^{-}$concentrations for anolyte and catholyte lead to a restructuring of the structure in the alcohol/water system, therefore, the proton exchange is accelerated and there is also only one general signal of mobile protons $\mathrm{EtOH}+\mathrm{H}_{2} \mathrm{O}$ asymmetric.

In this case, the ECA water intensifies the oxidation-reduction reactions when creating WAM, due to the increase of MC aldehydes and esters. Aldehydes are acetaldehyde, which is formed by oxidation of ethanol with oxygen. Esters are represented by ethyl acetate, by oxidation of part of acetaldehyde to acetic acid by oxygen and by the interaction of acetic acid with ethanol to form ethyl acetate.

After processing AC WAM on water softened by $\mathrm{Na}$-cationization (Figure 9), the resulting vodka is characterized by a single total signal of hydroxyl protons, $\mathrm{EtOH}+\mathrm{H}_{2} \mathrm{O}$, represented as a symmetric singlet with a chemical shift $\delta_{E t O H+H 2 O}=4.41 \mathrm{ppm}$. In the process of processing AC WAM in the anolyte (Figure 10), which is characterized by a total peak $\mathrm{EtOH}+\mathrm{H}_{2} \mathrm{O}$, represented as a symmetric singlet with $\delta_{\mathrm{EtOH}+\mathrm{H} 2 \mathrm{O}}=4.85 \mathrm{ppm}$. In the process of AC WAM treatment on the catholyte (Figure 11), ${ }^{1} \mathrm{H} N M R$ spectra of $\mathrm{OH}$-groups are characterized by a total peak $-\mathrm{EtOH}+\mathrm{H}_{2} \mathrm{O}$ with a chemical shift $\delta_{E t O H+H 2 O}=(4.77 ; 4.75) \mathrm{ppm}$. The form of the total signal is a distorted Gaussian with an extended base and a vertex that has one main high-field peak and an additional low-field peak.

When producing vodka on the EAR class «Lux», technological water must meet the requirements of the organization standard and have the following characteristics: dry residue - no more than $350 \mathrm{mg} / \mathrm{dm}^{3}$; hydrogen index - from 6.0 to 8.0 units $\mathrm{pH}$; total hardness - not more than $0.1 \mathrm{mmol} / \mathrm{dm}^{3}$; alkalinity total - from 1.0 to $2.0 \mathrm{mmol} / \mathrm{dm}^{3}$; ORP is not standardized.

Due to the conducted research, water after $\mathrm{Na}$-cationization has an elevated $\mathrm{pH}=7.18$ relative to drinking water $(\mathrm{pH}=6.91)$, as well as elevated $\mathrm{ORP}=\langle(+» 288.0 \mathrm{mV}$ for drinking water $(\mathrm{ORP}=\langle\langle+\rangle 269.0 \mathrm{mV})$. Anolyte and catholyte samples are characterized by a change in the $\mathrm{pH}$ and ORP levels relative to the initial values: with the anode ECA, the hydrogen index becomes more acidic $(\mathrm{pH}=2.43)$; ORP - increased to positive (oxidative) values $(\mathrm{ORP}=\langle++\rangle 451 \mathrm{mV})$; at catholit - the $\mathrm{pH}=11.08$ acquires a more alkaline reaction; $\mathrm{ORP}=\langle++\rangle 44.0 \mathrm{mV}$.

In Figure 12 is represented the dependence of hydrogen indicator of the ORP for water, WAM, WAM after AC without processing and after ECA. In this case, three areas of samples can be observed: $a_{0}$ - without treatment; $a_{1}$ - samples in the catholyte; $a_{2}$ - samples on anolyte.

It can be argued that in the process of creating vodka there is relaxation of the WAM in terms of the level of $\mathrm{pH}$ and ORP, which in this case are «markers» of stabilization. The values of $\mathrm{pH}$ and ORP tend to shift to a stationary area of values that will not undergo critical 
changes throughout the «life cycle» of the finished product, while maintaining optimal storage conditions. Although in real storage conditions, there is a slight increase in $\mathrm{pH}$ and decrease in ORP, which are already dependent on the interaction of the product with the glass in which the product is stored.

A slight change in the value of total alkalinity in $N a$-cationization $\left(4.12 \mathrm{mmol} / \mathrm{dm}^{3}\right)$ relative to drinking water $\left(5.38 \mathrm{mmol} / \mathrm{dm}^{3}\right)$ is a major disadvantage of this process. Therefore, in the process of ECA on anolyte there is a decrease in alkalinity to $0 \mathrm{mmol} / \mathrm{dm}^{3}$, and after ECA (catholyte) - an increase in alkalinity to $10.85 \mathrm{mmol} / \mathrm{dm}^{3}$. Therefore with the help of anolyte it is possible to further acidify the water to reduce the total alkalinity of water.

It can be concluded that the electrochemical reactions occurring in the anode and cathode chambers of the diaphragm electrolyzer lead to a change in the entire system of intermolecular interactions, with different charge states of molecules in the anolyte and catholyte leading to differences in the electron distribution, which affects the values of chemical shifts hydroxyl protons.

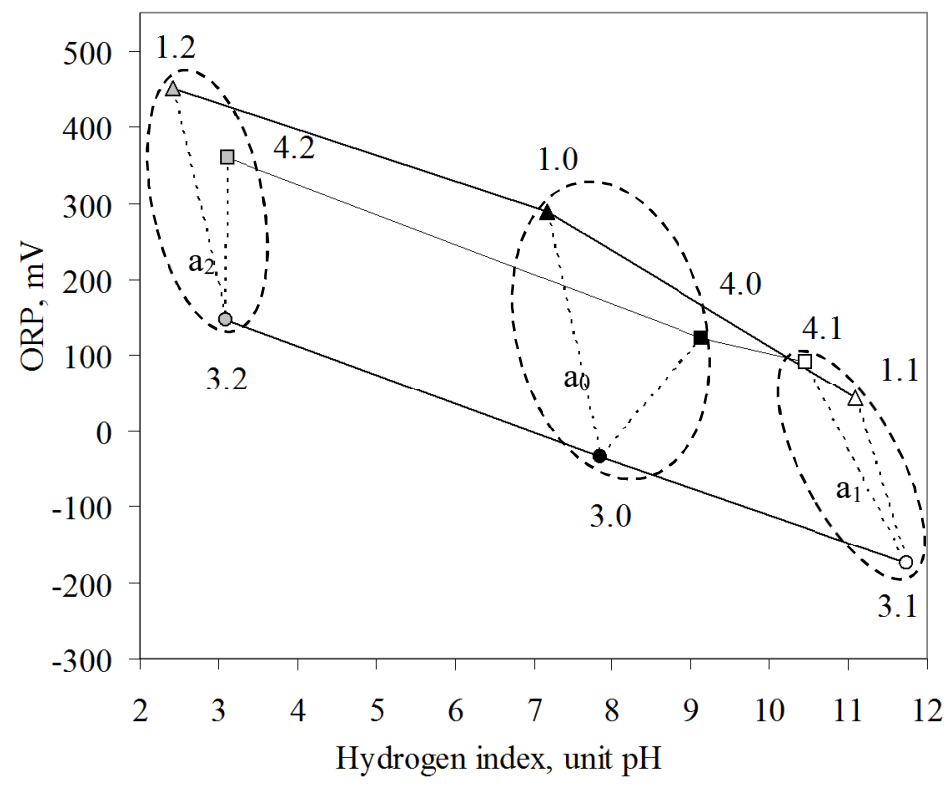

Figure 12. Dependence of hydrogen index of the ORP for water, WAM, WAM after AC without processing and after ECA:

$\mathrm{a}_{0}$ - area of samples without processing - control (1.0 - water softened by $\mathrm{Na}$-cationization, 3.0 WAM on softened water, 4.0 - WAM on water softened after treatment AC); $\mathrm{a}_{1}$ - area of samples after ECA (catholyte); a2 - area of samples after ECA (anolyte)

The vodka from the EAR class «Lux» should correspond to the following indicators: MC aldehydes in terms of acetic aldehyde - no more than $4 \mathrm{mg} / \mathrm{dm}^{3} ; \mathrm{MC}$ of fusel oil, calculated on the mixture of propyl, isobutyl and isoamilic alcohols - not more than $4 \mathrm{mg} / \mathrm{dm}^{3}$; MC esters in terms of acetic-ethyl ester - no more than $5 \mathrm{mg} / \mathrm{dm}^{3}$; volume fraction of methyl alcohol - not more than $0.01 \%$; alkalinity - from 0.5 to $3.5 \mathrm{~cm}^{3}$.

As water is softened by $\mathrm{Na}$-cationization and water softened after ECA - do not meet all 
the requirements of the normative documentation, the vodka created on this water, conditionally meets the requirements of regulatory documentation, except for alkalinity and MC aldehydes - for vodka on anolyte. In this case there are significant changes in the level of $\mathrm{pH}$ and ORP in the WAM in the catholyte after processing with AC. At the primary $\mathrm{pH}=11.75$ for the WAM, after the AC WAM processing at the catholyte, the $\mathrm{pH}$ level 10.45 , with the primary ORP $=\langle-\gg 174 \mathrm{mV}$, after the $\mathrm{AC}$ WAM treatment at the ORP cathode «+»» $92 \mathrm{mV}$.

It can be argued that at the stage of treatment of AC WAM in water softened by $\mathrm{Na}$ cationization and ECA there is a relaxation of the WAM, which results in the return of the values of $\mathrm{pH}$ and ORP to the new equilibrium values while simultaneously stabilizing the hydroxyl groups of protons of ethanol and water, due to generalizing of signals.

\section{Conclusions}

On the basis of the study, a fundamental difference was found between the behavior of WAM and vodka prepared on water softened by $\mathrm{Na}$-cationization and water treated by the ECA. Systems with unstable equilibrium were not detected. The system of alcohol/water with a constant equilibrium and a high degree of generalization of protons, as well as its characteristic exchange rates, is characteristic of the WAM from the EAR of the Luxury class and the water softened by $\mathrm{Na}$-cationization as well as the water that passed the ECA in the diaphragm electrolyzer.

Thus, experimental evidence is obtained of the dependence of the rate or time and nature of the establishment of the thermodynamic equilibrium due to the relaxation of the wateralcohol systems with the simultaneous stabilization of the hydroxyl group of water and ethanol protons.

The purpose of the work is to study the mechanism of establishing the equilibrium state of vodkas during the creation of water-alcohol mixtures in the process of electrochemical activation of technological water at the stage of $\mathrm{Na}$-cationization softening. Experimentally proved the dependence of the time and nature of the establishment of the thermodynamic equilibrium - the relaxation of the water-alcohol systems during the stabilization of the hydroxyl group of protons of ethanol and water.

Acknowledgements. The research and technical developments are executed by the international interuniversity team and are directly related to the direction of work of the target complex program of scientific, scientific and technical and innovation activity: «Creation of scientific bases of technological processes of water restoration to its natural structural and energy state» (The Ministry of Education and Science of Ukraine, № 0117U001244, 2017-2019).

\section{References}

1. Andoni Zuriarrain, Juan Zuriarrain, Mercedes Villar, Iñaki Berregi (2015), Quantitative determination of ethanol in cider by ${ }^{1} \mathrm{H}$ NMR spectrometry, Food Control, 50, pp. 758-762.

2. Anna Paola Minoja, Claudia Napoli (2014), NMR screening in the quality control of food and nutraceuticals, Food Research International, 63(B), pp. 126-131.

3. Arnold J.T. (2002), Early perceptions in nuclear magnetic resonance (NMR), Encyclopedia of nuclear magnetic resonance, John Wiley \& Sons.

4. Edwin D. Becker, Cherie L. Fisk, C.L. Khetrapal (2002), The development of NMR, 
Encyclopedia of nuclear magnetic resonance, John Wiley \& Sons.

5. Fan Zhu (2017), NMR spectroscopy of starch systems, Food Hydrocolloids, 63, pp. 611624.

6. Gloria del Campo, Juan Zuriarrain, Andoni Zuriarrain, Iñaki Berregi (2016), Quantitative determination of carboxylic acids, amino acids, carbohydrates, ethanol and hydroxymethylfurfural in honey by ${ }^{1} \mathrm{H}$ NMR, Food Chemistry, 196, pp. 1031-1039.

7. Gy. Batta, K.E. Köver, Cs. Szantaz, Jr. (1997), Methods for structure elucidation by highresolution NMR. Application to organic molecules of moderate molecular weight, Amsterdam, Lausanne, New York, Oxford, Shannon, Singapore, Tokyo, Elsevier.

8. $\mathrm{Hu}$ N., Wu D., Cross K. and other (2010), Structurability: A collective measure of the structural differences in vodkas, Journal of agricultural and food chemistry, 58, pp. 7394 7401.

9. Joana Pinto, Ana Sofia Oliveira, Joana Azevedo, Victor De Freitas, Paula Guedes de Pinho (2018), Assessment of oxidation compounds in oaked Chardonnay wines: A GC-MS and ${ }^{1} \mathrm{H}$ NMR metabolomics approach, Food Chemistry, 257, pp. 120-127.

10. Junsang Oh, Deok-Hyo Yoon, Jae-Gu Han, Hyung-Kyoon Choi, Gi-Ho Sung (2018), ${ }^{1} \mathrm{H}$ NMR based metabolite profiling for optimizing the ethanol extraction of Wolfiporia cocos, Saudi Journal of Biological Sciences, 25(6), pp. 1128-1134.

11. Kemeng Shi, Christian Marcus Pedersen, Zhaohui Guo, Yanqiu Li, Yingxiong Wang (2018), NMR studies of the tautomer distributions of d-fructose in lower alcohols/DMSO-d6, Journal of Molecular Liquids, 271, pp. 926-932.

12. Klaus Albert (2002), On-line LC-NMR and related techniques, Chichester, John Wiley \& Sons Ltd.

13. Kuzmin O., Tamarkina J., Shendrik T., Zubkova V., Koval O., Roman T. (2017), Production of active coal from pyrolyzed wood wastes by alkaline activation of $\mathrm{KOH}$, Ukrainian Food Journal, 6(3), pp. 443-458.

14. Kuzmin O., Shendrik T., Zubkova V. (2017), Substantiation of the conditions of obtaining porous carbon materials from pyrolyzed wood wastes by chemical activation of $\mathrm{H}_{3} \mathrm{PO}_{4}$, Ukrainian Food Journal, 6(1), pp. 103-116.

15. Kuzmin O., Suikov S., Niemirich O., Ditrich I., Sylka I. (2017), Effects of the water desalting by reverse osmosis on the process of formation of water-alcohol mixtures. ${ }^{1} \mathrm{H}$ NMR spectroscopy studies, Ukrainian Food Journal, 6(2), pp. 239-257.

16. Kuzmin O., Suikov S., Koretska I., Matiyashchuk O., Poliovyk V. (2017), Identification of equilibrium state of hydroxyl protons in vodkas by ${ }^{1} \mathrm{H}$ NMR spectroscopy, Ukrainian Food Journal, 6(2), pp. 314-336.

17. Latufa Youssouf, Laura Lallemand, Pierre Giraud, Faiza Soulé, Joël Couprie (2017), Ultrasound-assisted extraction and structural characterization by NMR of alginates and carrageenans from seaweeds, Carbohydrate Polymers, 166, pp. 55-63.

18. Nose A., Hamasaki T., Hojo M. and other (2005), Hydrogen bonding in alcoholic beverages (distilled spirits) and water-ethanol mixture, Journal of agricultural and food chemistry, 53, pp. 7074-7081.

19. Oliveira I.S., Bonagamba T.J., Sarthour R.S. and other (2007), NMR quantum information processing, Amsterdam, Oxford, Elsevier.

20. Raymond J. Abraham, Mehdi Mobli (2008), Modelling ${ }^{1} H$ NMR spectra of organic compounds. Theory, applications and NMR prediction software, John Wiley \& Sons Ltd., Wiltshire.

21. Reinhard Meusinger (2010), NMR-Spektren richtig ausgewertet : 100 Übungen für Studium und Beruf, Heidelberg, Dordrecht, London, New York, Springer.

22. Riad Ababneh, Ahmad Telfah, Inshad Jum'h, Mohammad Abudayah, Roland Hergenröder (2018), ${ }^{1} \mathrm{H}$ NMR spectroscopy to investigate the kinetics and the mechanism of proton charge carriers ionization and transportation in hydrophilic/hydrophobic media: Methyl 
sulfonic acid as a protonic ion source in water/alcohol binary mixtures, Journal of Molecular Liquids, 265, pp. 621-628.

23. R. Dutta Majumdar, T. Montina, O.C. Mullins, M. Gerken, P. Hazendonk (2017), Insights into asphaltene aggregate structure using ultrafast MAS solid-state ${ }^{1} \mathrm{H}$ NMR spectroscopy, Fuel, 193, pp. 359-368.

24. Roberts J.D. (2002), Organic chemistry applications, in Grant, D.M., Harris, R.K. (ed.) Encyclopedia of nuclear magnetic resonance, Chichester: John Wiley \& Sons, Ltd, pp. 3386-3400.

25. Rui-Yao Li, Xiao-Wei Zheng, Xin Zhang, Zheng Yan, Bei-Zhong Han (2018), Characterization of bacteria and yeasts isolated from traditional fermentation starter (FenDaqu) through a ${ }^{1} \mathrm{H}$ NMR-based metabolomics approach, Food Microbiology, 76, pp. 1120.

26. Rutledge D.N. (1996), Signal treatment and signal analysis in NMR, Amsterdam, Lausanne, New York, Oxford, Shannon, Tokyo, Elsevier.

27. Richards S.A., Hollerton J.C. (2011), Essential practical NMR for organic chemistry, Chichester, John Wiley \& Sons.

28. Thomas Kuballa, Thomas Hausler, Alex O. Okaru, Maria Neufeld, Dirk W. Lachenmeier (2018), Detection of counterfeit brand spirits using ${ }^{1} \mathrm{H}$ NMR fingerprints in comparison to sensory analysis, Food Chemistry, 245, pp. 112-118.

29. Holzgrabe U., Wawer I., Diehl B. (2008), NMR spectroscopy in pharmaceutical analysis, edited by B. Diehl, Amsterdam, Oxford, Elsevier.

30. Yingjie $\mathrm{Xu}, \mathrm{Wu}$ Qian, Qiongqiong Gao, Haoran Li (2012), Prediction of vapor-liquid equilibria of alcohol+hydrocarbon systems by ${ }^{1} \mathrm{H}$ NMR spectroscopy, Chemical Engineering Science, 74, pp. 211-218.

31. Yoshimasa Mori, Mitsumasa Takahashi, Yasushi Ohno, Ryuhei Okura, Hidetoshi Arima (2018), Identification of molecular-interaction sites between lowly hydrolyzed polyvinyl alcohols and indomethacin by NMR spectroscopy, International Journal of Pharmaceutics, 549(1-2), pp. 456-465.

32. Yunfei Yuan, Yupeng Zhao, Jiali Yang, Yueming Jiang, Bao Yang (2017), Metabolomics' analyses of banana during postharvest senescence by ${ }^{1} \mathrm{H}$-high resolution-NMR, Food Chemistry, 218, pp. 406-412. 